\title{
Robert Kantor
}

The Pontifical University of John Paul II in Cracow, Poland

\section{Socjalizacja - wyzwanie współczesności (Socialización - reto contemporáneo) bajo la dirección de J. Stala}

\section{Ed. Biblos, Tarnów 2010, pp. 464, ISBN 978-83-733294-0-9}

La socalización es un proceso de influjo entre una persona y sus semejantes, un proceso que resulta de aceptar las pautas de comportamiento social y de adaptarse a ellas. Este desarrollo se observa no solo en las distintas etapas entre la infancia y la vejez, sino también en personas que cambian de una cultura a otra, o de un status social a otro, o de una ocupación a otra. La socialización se puede describir desde dos puntos de vista: objetivamente; a partir del influjo que la sociedad ejerce en el individuo; en cuanto proceso que moldea al sujeto y lo adapta a las condiciones de una sociedad determinada, y subjetivamente; a partir de la respuesta o reacción del individuo a la sociedad. La socialización es vista por los sociólogos como el proceso mediante el cual se inculca la cultura a los miembros de la sociedad, a través de él, la cultura se va transmitiendo de generación en generación, los individuos aprenden conocimientos específicos, desarrollan sus potencialidades y habilidades necesarias para la participación adecuada en la vida social y se adaptan a las formas de comportamiento organizado característico de su sociedad.

El hecho de que el hombre está formando la sociedad en la que vive es un hecho de común reconocimiento, así como también de que la sociedad de su parte tiene influencia sobre el hombe, que a ella pertenece. Dicha influencia mutua pertenece al fundamental experiencia humana y siempre se consideraba como algo importante para su existencia. En las épocas anteriores la experiencia de lo social de manera natural se componía con la vida humana y proceso educativo. El hombre fue introducido a la vida social, en cambio la sociedad de alguna manera se sentía responsable por esta influencia. Dicho proceso no era llevado con una metodología bien hecha, aunque su efectividad es algo digno de reconocer. En 
la segunda parte del siglo XIX ha empezado el estudio metodológico de esta problemática llamada la socialización. A parte de la noción general como también de muchos estudios e investigaciones, la socialización sigue siendo entendida, interpretada de manera no unívoca. Por lo tanto hay un reto, que hay que llevarlo para precizar su sentido teniendo en cuenta el servicio de formación y desarrollo de la persona humana, sobre todo en su dimensión social. Para efectuarlo hay que elaborar en el hombre una adecuada estructura de motivación, cualidades, posturas y competencias. Se trata de enfrentar las exigencias del ambiente y su propio organismo biologico - espiritual. Dicho proceso lleva consigo la entrada del individuo en la cultura porque el proceso de hacerse el hombre es una función de la experiencia social y cultural. La socialización exige ciertos mecaniosmos, que la consruyen, el contenido y el objetivo. Solamente una conjunta visión de la socialización pede tener la esperanza que se esconde en todas las búsquedas, es decir una esperanza para la formación del hombre de una madura personalidad que goza de su identidad, viviendo en plena sumergencia en las relaciones sociales llevando esfuerzo de su formación dignos del hombre. En la Iglesia de Polonia no existe hasta momento el problema de la socialización en forma sistemática, tampoco se encuentran las investigaciones de tal problemática, es decir no se fijó lugar que debiera ocupar en la reflexión científica y de que manera pudiera participar en la misión de la Iglesia. Quizá esto es fruto de la situación política e ideológica en Polnia.

En las páginas de la presente publicación "Socialización-reto contemporáneo" bajo la redacción de prof. Józef Stala, como también en planeadas en el futuro publicaciones en la serie "Formación social" se pretende dar la respuesta, cuyo objetivo existe en abarcar todo lo que necesita la Iglesia que actua en el mundo contemporáneo - el mundo, que es social por su naturaleza. La problemática se cierra en tres partes. En la primera parte: "Antropología y teología del servicio" se encuentran los siguientes temas: Janusz Królikowski, Católico y la participación en la vida social; Wiesław Przygoda, Fundamentos teológicos del trabajo social - caritativo; Henryk Szmulewicz, Motivación del trabajo social: respuesta al don de la misericordia de Jesús; Elżbieta Okońska, Diálogo social al servicio del hombre. Algunos aspectos; Branislav Kl'uska, Idea de la conversión cristiana en el proceso de resocialización; Czesław Noworolnik, Fundamentos antropológicos y teológicos de la personalidad del voluntariado cristiano según Juan Pablo II; Tadeusz Michalik, Formación catequética de la conciencia como uno de los caminos de ayuda al hombre; Gabriela Janikula, Implicaciones pastorales y catequéticas de las "Cartas" a los enfermos; Michał Drożdż, Vejez y sus necesidades de asistencia en la perspectiva antropológica y ética. En la 
segunda parte: "Iglesia servidora" se habla de temas: Robert Biel, Hacia Iglesia servidora; Krzysztof Bułat, Actividad caritativa de la Iglesia según la encíclica de Benedicto XVI Deus Caritas Est; Robert Kantor, Actividad caritativa en el derecho canónico y eclesiástico. Aspecto normativo; Sylwester Jaśkiewicz, Ayuda al hombre y una visión reductiva de la Iglesia y su misión según la teología de liberación; Edmund Robek, Cáritas - función redemptora de la Iglesia parroquial; Krzysztof Czermak, Obra de la promoción humana como elemento integral de la actividad misionera de la Iglesia de Tarnów; Jerzy Jurkiewicz, Actividad caritativa de la Iglesia de Milán en los tiempos de obispo Ambrosio. En cambio en la tercera parte: "Posturas servidoras" se presentan los siguientes temas: Beata Szluz, Actividad en le trabajo social - retos contemporáneos; Magdalena Butrymowicz, Fundamentos de derecho de la asistencia social en los tiempos de vigésimo años entre guerras - análisis de los actos normativos; Konrad Dyrda, Jóvenes y voluntariado; Marta Lausch-Chudy, Fuerza educativa del voluntariado; Marta Komorowska-Pudło, Transtornos de la vida familiar - algunos campos de ayuda; Dorota Kornas-Biela, Padres sin edad - retos para la pedagógica social; Barbara Rozen, Pedagógica de la función servidora al hombre sufrido; Krzysztof Sosna, Jóvenes en el servicio a los demás - "educación hacia la postura pro social"; Józef Stala, Reconocimiento desde principio de una adecuada ayuda una característica de personas minusválidas intelectualmente.

La socialización supone capacidad de relacionarse con los demás; el ser humano no se realiza en solitario, sino en medio de otros individuos de su misma especie, de forma que si careciera de esta relación de períodos fundamentales de su evolución, no se humanizaría.

La socialización es convivencia con los demás, sin la cual el hombre se empobrecería y se privaría de una fuente de satisfacciones básicas para el equilibrio mental. Esta convivencia cumple con el objetivo de llenar las necesidades fundamentales de afecto, de protección, de ayuda, etc. La convivencia es por otra parte, la mejor prueba de que la socialización es correcta y de que el individuo se ha abierto a los demás. La socialización es interiorización de normas, costumbres, valores y pautas, gracias a la cual el individuo conquista la capacidad de actuar humanamente.

En consecuencia, la socialización podría definirse como un proceso de interacción entre la sociedad y el individuo, por el que se interiorizan las pautas, costumbres y valores compartidos por la mayoría de los integrantes de la comunidad, se integra la persona en el grupo, se aprende a conducirse socialmente, se adapta el hombre a las instituciones, se abre a los demás, convive, con ellos 
256 Volume 1(2011) Number 1

y recibe la influencia de la cultura, de modo que se afirma el desarrollo de la personalidad.

La monografía es un excelente trabajo que ayudará no solo a los profesionales que se ocupan diariamente de las investigaciones de este tema, sino también a todos los hombres, pues somos, por naturaleza seres humanos que no nos realizamos en solitario, sino en medio de otros. 